\title{
Hemophagocytic Lymphohistiocytosis Syndrome in Dengue Hemorrhagic Fever: Correspondence
}

\author{
Beuy Joob • Viroj Wiwanitkit
}

Received: 17 May 2014 / Accepted: 3 December 2014 / Published online: 16 January 2015

(C) Dr. K C Chaudhuri Foundation 2015

To the Editor: The recent report on "Hemophagocytic lymphohistiocytosis (HLH) and dengue in pediatric popultation" is very interesting [1]. Raju et al. concluded that dengue with multi-organ dysfunction is commonly concurrent to HLH in the marrow and hence, an early diagnosis based on clinical, laboratory and bone marrow evaluation is significant [1]. In fact HLH is an uncommon but forgotten problem that can be seen in a patient with dengue $[2,3]$. This condition can be fatal and early diagnosis is needed. However, it should be noted that HLH can be due to other conditions such as sepsis $[4,5]$. In the present report, as a retrospective study, Raju et al. failed to rule out the effect of possible concomitant disorder. As Raju et al. noted that the problem is common in cases with multiple organ dysfunction [2], it is expected that there might be many cases with sepsis.

Conflict of Interest None.

Source of Funding None.

\section{References}

1. Raju S, Kalyanaraman S, Swaminathan K, Nisha A, Praisid S. Hemophagocytic lymphohistiocytosis syndrome in dengue hemorrhagic fever. Indian J Pediatr. 2014. doi:10.1007/s12098-0141425-4.

2. Sharp TM, Gaul L, Muehlenbachs A, Hunsperger E, Bhatnagar J, Lueptow R, et al; Centers for Disease Control and Prevention (CDC). Fatal hemophagocytic lymphohistiocytosis associated with locally acquired dengue virus infection - New Mexico and Texas, 2012. MMWR Morb Mortal Wkly Rep. 2014;63:49-54.

3. De Koninck AS, Dierick J, Steyaert S, Taelman P. Hemophagocytic lymphohistiocytosis and dengue infection: rare case report. Acta Clin Belg. 2014;69:210-3.

4. Raschke RA, Garcia-Orr R. Hemophagocyticlymphohistiocytosis: a potentially underrecognized association with systemic inflammatory response syndrome, severe sepsis, and septic shock in adults. Chest. 2011;140:933-8.

5. Duran-Bedolla J, Montes de Oca-Sandoval MA, Saldaña-Navor V, Villalobos-Silva JA, Rodriguez MC, et al. Sepsis, mitochondrial failure and multiple organ dysfunction. Clin Invest Med. 2014;37:E58-69.

B. Joob $(\square)$

Sanitation 1 Medical Academic Center, Bangkok, Thailand

e-mail: beuyjoob@hotmail.com

V. Wiwanitkit

Department of Tropical Medicine and Public Health, Hainan Medical

University, Haikou, China 